\title{
WLAN \& WIMAX APPLICABLE UWB MINI PATCH ANTENNA COMPRISING METAMATERIAL WITH GROUND SLOTTED CHARACTERISTICS
}

\author{
Ritesh Kumar Saraswat ${ }^{1}$, Ashutosh Pareek ${ }^{2}$, Udal Singh Dagur ${ }^{3}$ and Vishruti Arya ${ }^{4}$
}

\begin{abstract}
In this article a ultra wide band miniaturized patch antenna is proposed which is fed by Microstrip fed line. This proposed antenna is fabricated through design pro machine on FR4 lossy substrate and simulated through CST microwave studio. This projected antenna is responding at 3.1 to $10.6 \mathrm{GHz}$. This miniaturization is done through the introduction of fractal geometry. A good agreement between simulation and measured result is found. The active patch area and antenna volume is miniaturized up to $45.33 \%$ and $30.2 \%$ severally. The proposed antenna falls in WLAN and WiMAX frequency bands.
\end{abstract}

Keywords - Miniaturization slotted ground structure, WiMAX, WLAN, ultra wideband, fractal, metamaterial.

\section{INTRODUCTION}

In today's word of electronics high data communication rates with less power consumption sare the essential parts for short range indoor communication system like wireless personal area network, remote sensing, image radar. The requirements can be fulfilled by using operating the proposed structure at UWP. The frequency spectrum which is used in this protected antenna is given by federal communication commission for commercial communication applications in 2002. The head quarter of the FCC is in US. Although there are several methods have been introduced to miniaturized the active patch area and volume of Microstrip antennas like fractal shapes of radiating elements defected Microstrip structure (DMS), dielectric substrate of high permittivity, defected ground structure (DGS). But in this single printed mini patch antenna we are using the technique of the fractal. Fractalization along with band notch characteristics gives multi band resonance to the proposed antenna design for WiMAX and WLAN application. (2.4-2.5GHz, 5.150-5.250 GHz, 5.725-5.825GHz). certain properties like miniaturization , optimum band width, gain enhancement and better radiation performance. are provided by the multi band metamaterial antennas. There are various metamaterial inspired techniques such as split ring resonator(SRRs), based monopole antennas and complementary split ring resonator loaded substrate and partial metamaterial loading.

Impedance band width of miniaturized patch antenna is observed $139 \%(2.58-01.38 \mathrm{GHz})$ for simulation and $132 \%$ (2.95-14.28 GHz) for measurement. This projected antenna resonates $2.45-14.42 \mathrm{GHz}$ for conventional and 2.5814.38 GHz for miniaturized antenna. By using slotted ground structure approach we get WLAN and WiMAX frequency bands $2.39-2.67 \mathrm{GHz}(11.1 \%), 2.87-5.28 \mathrm{GHz}(59.1 \%)$ and $5.58-6.01 \mathrm{Gz}(7.4 \%)$ which is under simulation and $2.41-2.52 \mathrm{GHz}(4.5 \%), 3.1-5.26 \mathrm{GHz}(51.1 \%)$ and $5.69-5.91 \mathrm{GHz}(3.8 \%)$ in measurement which is followed by meta material SRR loading.

\footnotetext{
${ }^{1}$ Department of Electronics and Communication Engineering M.L.V.Textile \& Engineering College, Bhilwara, Rajasthan, India

${ }^{2}$ Department of Electronics and Communication Engineering Career Point University, Kota, Rajasthan, India

${ }^{3}$ Department of Electronics and Communication Engineering M.L.V.Textile \& Engineering College, Bhilwara, Rajasthan, India

${ }^{4}$ Department of Electronics and Communication Engineering M.L.V.Textile \& Engineering College, Bhilwara, Rajasthan, India
} 
The comparison of radiation pattern VSWR, gain is made with their simulated and measured ones in upcoming segment through which a good agreement is seen between measured and simulated the ' $\mathrm{S}_{1}$ '.

\section{MINITURIZED UWB ANTENNA DESIGN}

The configuration of the design is described below:-

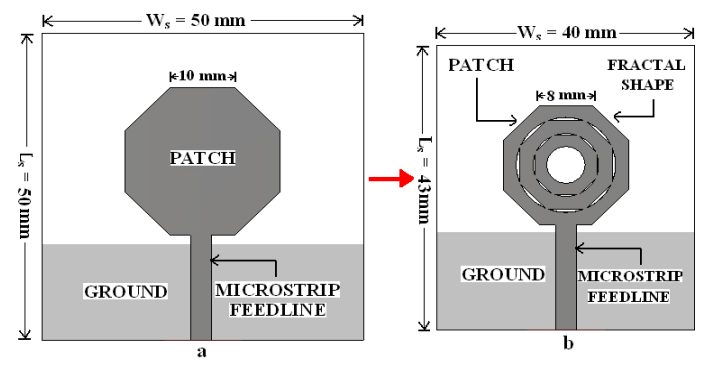

(A) Fr ont view of structure

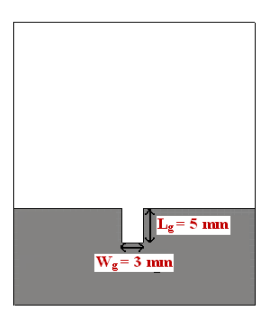

(B) Back view of proposed structure e $b$ '

Figure 1 Configuration of the proposed miniaturized UWB antenna. (a) Front view of structure, (b) back view of structure

The projected antenna is constructed on FR4 substrate $\left(43 * 40 \mathrm{~mm}^{2}\right)$. Which has the permittivity of 4.3 and thickness of $1.6 \mathrm{~mm}$. configuration $\mathrm{b}$ is obtained by fractalising configuration a, which results in active patch area and volume. There is a ground plane at the bottom of the substrate with the electrical dimensions of $15.5 * 40 \mathrm{~mm}^{2}$ and height $0.01 \mathrm{~mm}$. here octagonal shaped patch is working as radiating element which is of branch length $8 \mathrm{~mm}$ fed by $50 \mathrm{ohm}$ Microstrip feed line with the length and width of $17 \mathrm{~mm}$ and $3.16 \mathrm{~mm}$ respectively .

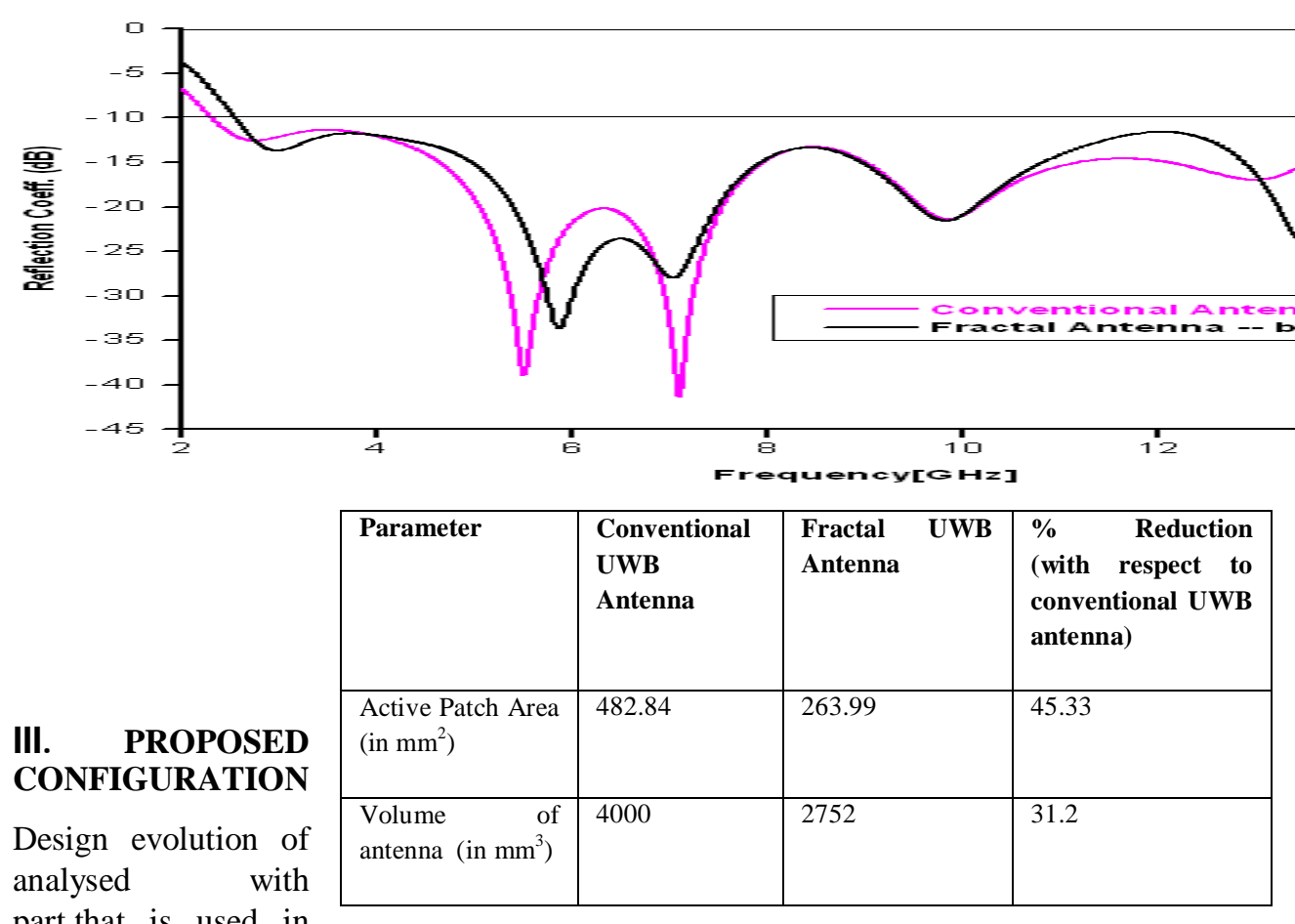

ANTENNA

proposed antenna is proposed SRR in this WLAN and WIMAX 
applications. As shown in diagram 3. By executing the slotted ground structure and proposed rectangular SRR the miniaturized UWB monopole antenna can be obtained in to other frequency bands of WLAN and WIMAX.

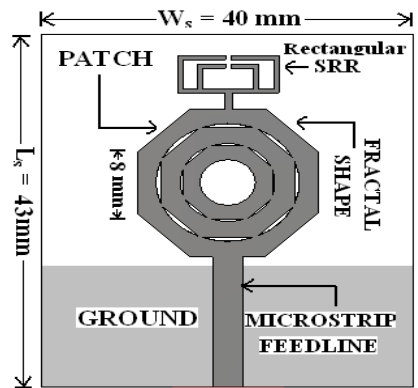

(a)

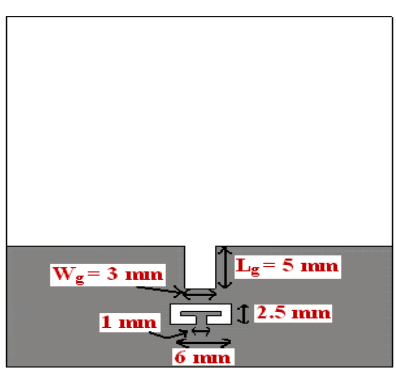

(b)

Figure 3 Configuration of the proposed miniaturized UWB antenna. (a) Front view of structure, (b) back view of structure.

By applying one or more conducting rings on a dielectric substrate with slits etched reverse of each other. We received respective rectangular SRR. As shown in diagram 3. The ordinary rectangular SRR renovated in suc $h$ a way that preserving a common loop on one side and bottom splits on other side.

\begin{tabular}{|l|l|}
\hline Parameters & Optimized Value (in $\mathbf{~ m m}$ ) \\
\hline Length of line from patch to SRR & 2 \\
\hline Width of line from patch to SRR & 1 \\
\hline Length of major rectangular ring & 4.5 \\
\hline Width of major rectangular ring & 10 \\
\hline Length of minor rectangular ring & 3.5 \\
\hline Width of minor rectangular ring & 6 \\
\hline Gap between rings & 0.5 \\
\hline Thickness of rings & 0.5 \\
\hline
\end{tabular}

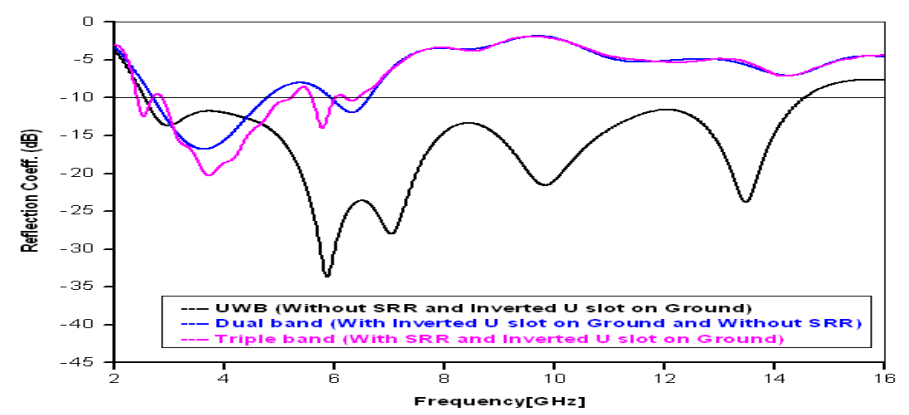

Fig 4- Comparison of reflection coefficient for case I ,II \& III.

To reduce the frequencies outside the required frequency band an inverted $\mathrm{U}$ type slotted ground structure of miniaturized UWB antenna is constructed which act as a filter. By including the case with and or without inverted U slot on ground plane, observation is received. An additional current path is generating in antenna structure due to slots in antenna structure,that disturb the current flow in antenna structure. Th9is additional current path leads to the dual band operation. The simulated input reflection coefficient $S_{11}$ of proposed antenna for three cases, where in case-I it formed UWB range $2.58-14.38 \mathrm{GHz}(139 \%)$, for case-II dual bands $2.8-4.71 \mathrm{GHz}$ (5.d) \& $5.78-6.62 \mathrm{GHz}$ (13\%) and for case-III triple bands $2.39-2.67 \mathrm{GHz}(11.1 \%), 2.87-5.28 \mathrm{GHz}(59.1 \%)$ and $5.58-6.01 \mathrm{GHz}(7.4 \%)$.

simulation of proposed antenna is done on CST microwave studio (MWS) and fabrication is done on low cost FR4 substrate having dielectric constant $€_{\mathrm{r}}=4.3$, thickness $\mathrm{h}=1.6 \mathrm{~mm}$ and loss tangent, $\tan \delta$ about 0.025 with optimized directions as shown diagram 5 . 


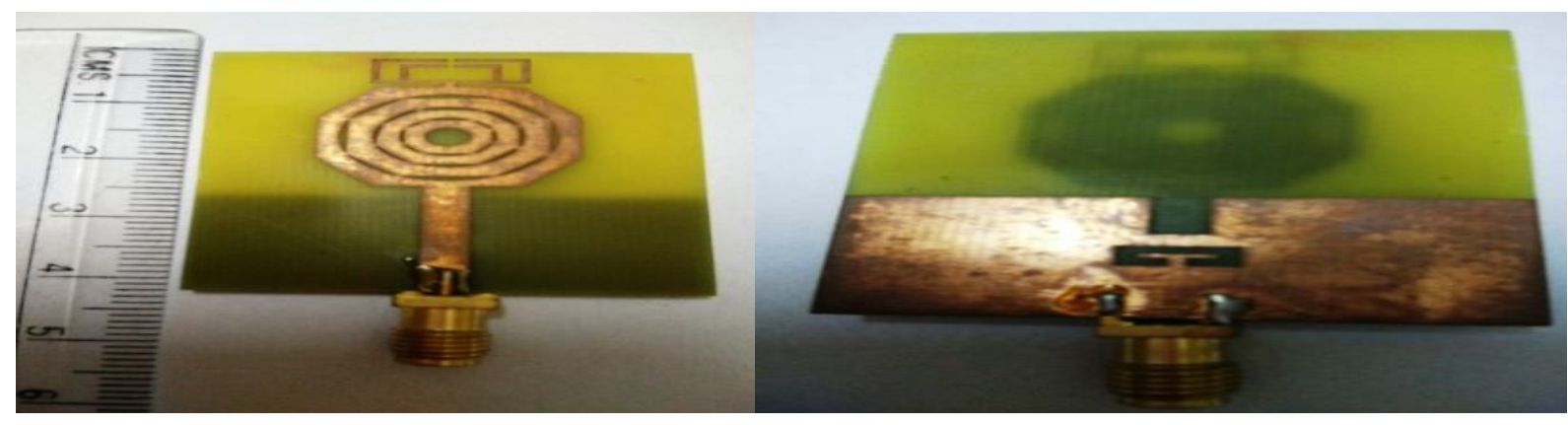

Figure 5 Image of the fabricated split ring loaded triple band antenna 'c' (a) top view; (b) bottom view.

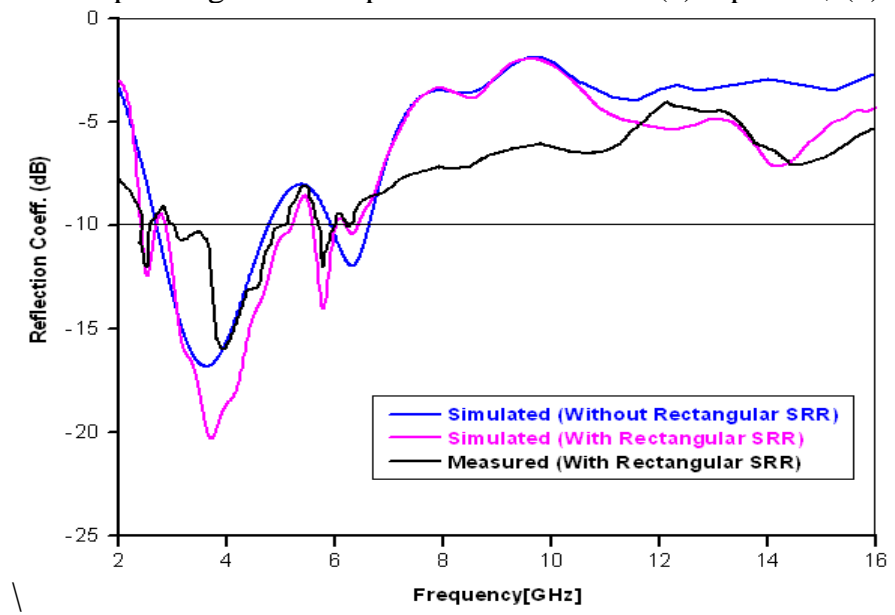

Figure 6 Simulated and measured reflection coefficient $S_{11}$ of the proposed antenna with and without the rectangular SRR.

By this approach an octagonal shape fractal UWB antenna is designed first and subsequently redesigned.

A triple band generates instead of exciting dual band system, when a rectangular split ring resonator (SRR) structure is imported with octagonal shape patch. $9.8 \%$ decrease in fundamental resonance bandwidth is observed when simulated result in case of "without rectangular SRR" is associated with measured result in case of "with rectangular SRR" of proposed UWB antenna. The impedance bandwidth is obtained in triple band under simulation it is achieved as $11.1 \%(2.39-2.67 \mathrm{GHz}), 59.1 \%(2.87-5.28 \mathrm{GHz})$ and $7.4 \%(5.58-6.01 \mathrm{GHz})$ where as in measurement it is achieved as $4.5 \%(2.41-2.52 \mathrm{GHz}), 51.1 \%(3.12-5.26 \mathrm{GHz})$ and $3.8 \%(5.69-5.91 \mathrm{GHz})$, so measured bandwidth is decrease in first, second and third resonant band as $6.6 \%, 8 \%$ and $3.6 \%$ respectively. Clearly from result we needs the wireless standards WLAN and WiMAX requirements.

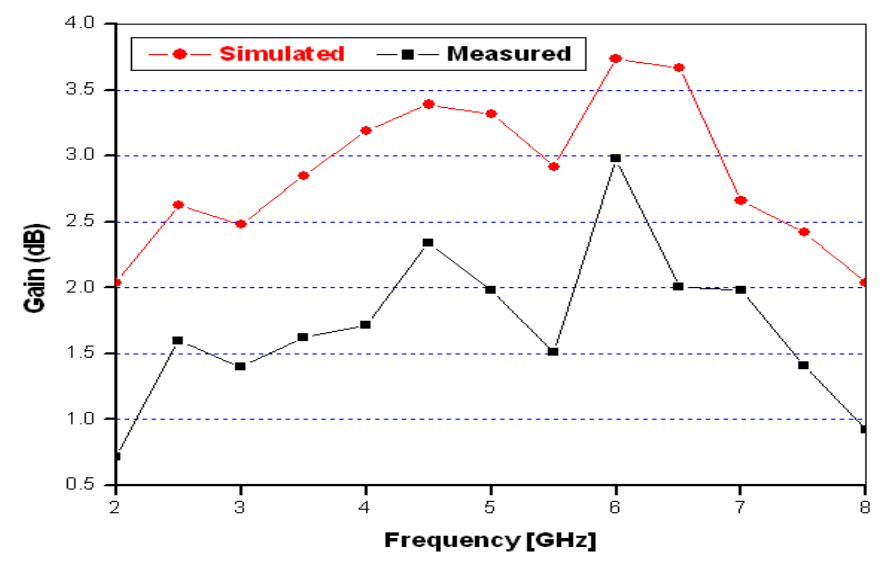


Figure 7 Simulated and measured gain of the proposed antenna

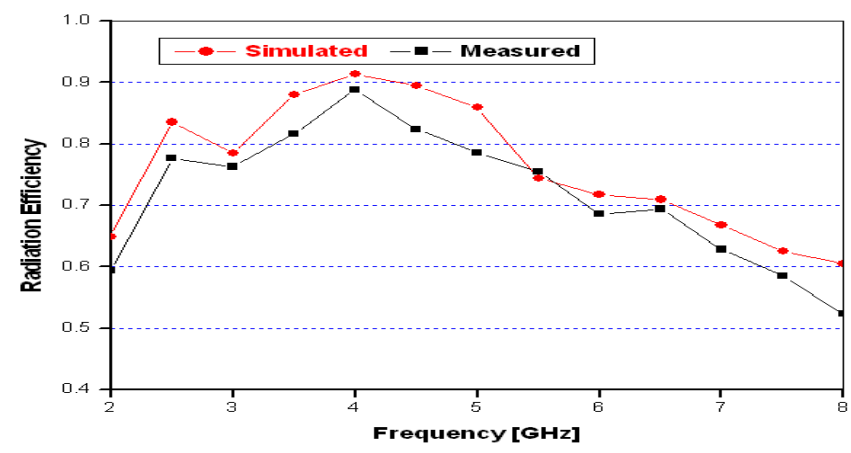

Figure 8 Simulated and measured radiation efficiency of the proposed antenna.

Under simulation radiation efficiency varies from $91.5 \%$ to61.2\% and in measurement varies from $88.7 \%$ to $52.8 \%$. it is observed that radiation efficiency remain same above $70 \%$ in all the operating bands as $72.8 \%, 82.4 \%, 79.2 \%$ and $72.1 \%$ radiation efficiency is observed for WLAN and WiMAX frequency bands of 2.4, 3.5, 5 and $5.8 \mathrm{GHz}$.

For both cross polarization and co-polarization, the radiation frequencies are plotted. The radiation pattern for the antenna proposed here at $2.4 \mathrm{GHz}, 3.5 \mathrm{GHz}, 5 \mathrm{GHz}$ and $5.8 \mathrm{GHz}$ are shown in diagram 9 for E-plane and $\mathrm{H}$ - plane for both the cases of simulated and measurement. We can observe that the radiation pattern for $\mathrm{H}$ plane seems to be omnidirectional. Whereas the radiation pattern for E- plane are dipole like patterns .for both $\mathrm{E}$ - plane and $\mathrm{H}$ - plane patterns, cross polarization level are achieved lower than $-15 \mathrm{~dB}$ for every required frequency. The radiation patterns of both explained in E - plane for cross polarization and co-polarization have shown in appreciable understanding with the slide difference caused by assembly misalignments.
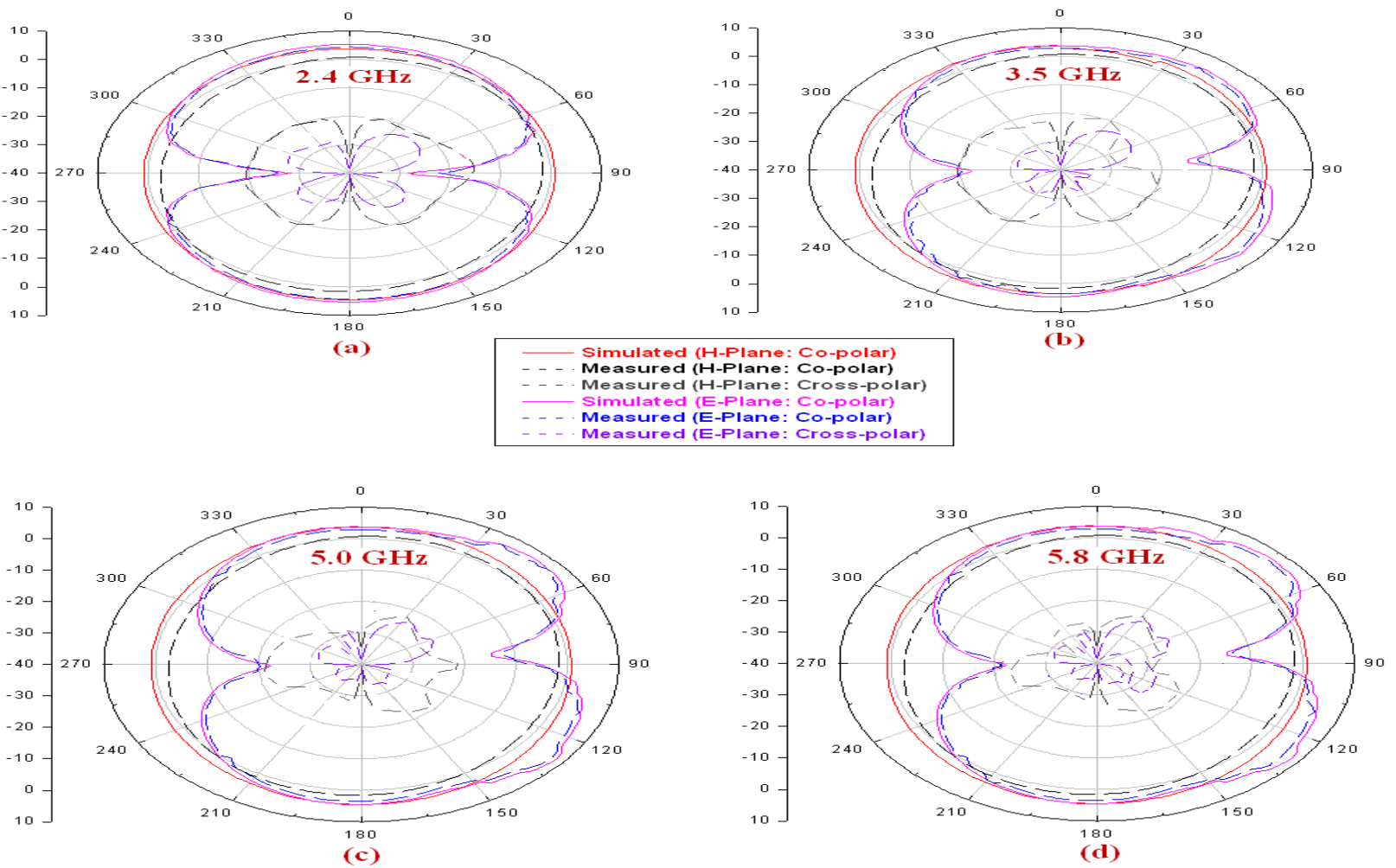

Figure 9 Simulated and Measured E \& H-Plane radiation patterns of the proposed antenna at; (a) $2.4 \mathrm{GHz}$ (b) 3.5 $\mathrm{GHz}(\mathrm{c}) 5.0 \mathrm{GHz}$ and (d) $5.8 \mathrm{GHz}$. 


\section{IV.CONCLUSION}

A miniaturized octagonal shape mini patch antenna is fabricated, simulated and measured successfully. Fabrication and simulation is done through design pro machine and CST microwave studio respectively. Results are obtained through network analyzer. To meet the requirements of WLAN and WI-MAX, the operating frequencies of the projected antenna are 2.4, 3.5, 5.0 and 5.8 GHz. The antenna characteristics are achieved with good impedance matching at these frequencies. In $\mathrm{H}$ - plane radiation pattern is found to be omnidirectional radiation characteristics in $\mathrm{H}-$ plane in accordance with the required frequencies of the wireless communication system. And this projected antenna can be used in the wireless applications of WLAN and WiMAX.

\section{REFERENCES}

[1] [1]. Federal Communications Commission, Revision of part 15 of the commission's rules regarding ultra-wide band transmission systems, Technical Report, ET-Docket 98-153, FCC02-48, FCC, Washington, DC, April 2002.

[2] [2]Ritesh K. Saraswat, and Mithilesh Kumar, “A Frequency Band Reconfigurable UWB Antenna for High Gain Applications,” Progress In Electromagnetics Research B, Vol. 64, 29-45, 2015.

[3]. Chakraborty, M., B. Rana, P. Sarkar, and A. Das, "Size reduction of microstrip antenna with slots and defected ground structure," International Journal of Electronics Engineering, Vol. 4, No. 1, 61-64, 2012.

[4]. Elftouh, H., N. A. Touhami, M. Aghoutane, S. El Amrani, A. Tazon, and M. Boussouis, "Miniaturized microstrip patch antenna with defected ground structure," Progress In Electromagnetics Research C, Vol. 55, 25-33, 2014.

[5] Hanae Elftouh*, Naima A. Touhami, and Mohamed Aghoutane, "Miniaturized Microstrip Patch Antenna with Spiral Defected Microstrip Structure” Progress In Electromagnetics Research Letters, Vol. 53, 37-44, 2015.

[3] [6] Ritesh K. Saraswat, and Mithilesh Kumar, "Miniaturized Slotted Ground UWB Antenna Loaded with Metamaterial for WLAN and WiMAX Applications,” Progress In Electromagnetics Research B, Vol. 65, 65-80, 2016.

[7] C. Mahatthanajatuphat, S. Saleekaw, and P. Akkaraekthalin, "A rhombic patch monopole antenna with modified minkowski fractal geometry for UMTS, WLAN, and mobile WIMAX application” Progress In Electromagnetics Research Letters, PIER 89,57-74, 2009.

[8] Sika Shrestha, Seong Ro Lee, and Dong-You Choi, "New Fractal-Based Miniaturized Dual Band Patch Antenna for RF Energy Harvesting" International Journal of Antennas and Propagation, Vol. (2014), 2014.

[9] Xu Y, Jiao Y-C, Luan Y-C, "Compact CPW-fed printed monopole antenna with triple band characteristics for WLAN/WiMAX applications," Electron Lett 2012;48(24):1519-20.

[10] Li X, Shi X-W, Hu W, Fei P, Yu J-F, "Compact triband ACS fed monopole antenna employing open ended slots for wireless communication," IEEE Antennas Wirel Propag Lett 2013;12:388-91.

[11] Liu P, Zou Y, Xie B, Liu X, Sun B, "Compact CPW fed tri band printed antenna with meandering split ring slot for WLAN/WiMAX applications,” IEEE Antennas Wirel Propag Lett 2012;11:1242-4.

[12] Xu H-X, Wang G-M, Lv Y-Y, Qi M-Q, Gao X, Ge S, "Multi frequency monopole antennas by loading metamaterial transmission lines with dual-shunt branch circuit," Prog Electromagn Res 2013;137:703-25.

[13] Xu H-X, Wang G-M, Qi M-Q, "A miniaturized triple-band metamaterial antenna with radiation pattern selectivity and polarization diversity," Prog Electromagn Res 2013;137:275-92.

[14] Basaran SC, Erdemli YE, “A dual band split ring monopole antenna for WLAN applications,” Microw Opt Technol Lett 2009;51(11):26858.

[15] Dong Y, Toyao H, Itoh T, "Design and characterization of miniaturized patch antennas loaded with complementary split ring resonators," IEEE Trans Antennas Propag 2012;60(2):772-5.

[16] Xiong J, Li H, Jin Y, Sailing H, "Modified TM020 mode of a rectangular patch antenna partially loaded with metamaterial for dual band applications," IEEE Antennas Wireless Propag Lett 2009;8:1006-9.

[17] Zhu J, Eleftheriades GV, "Dual band metamaterial inspired small monopole antenna for WiFi applications,"Electron Lett 2009;45(22):1104-6.

[18] Computer Simulation Technology - CST (Microwave Studio MWS) Version-2014. 